Jurnal Pengajian Melayu - JOMAS, Jilid 32(1), 2021: 1-14

\title{
WACANA ESTETIKA ISLAM DALAM SASTERA KANAK-KANAK INDONESIA ERA ORDE BARU TAHUN 1980-AN
}

\author{
(ISLAMIC AESTHETIC DISCOURSE IN INDONESIAN CHILDREN'S LITERATURE IN THE \\ ERA OF THE 1980'S NEW ORDER)
}

\author{
Dwi Susanto \\ dwisastra81@gmail.com \\ Albertus Prasojo \\ prasojo@staff.uns.ac.id \\ Rianna Wati \\ riannawati@staff.ens.ac.id \\ Murtini \\ murtiniibu@gmail.com \\ Universitas Sebelas Maret, Kota Surakarta \\ Indonesia
}

Received: 20 November 2020; Accepted: 8 April 2021

\begin{abstract}
This research focused on the spread of aesthetic discourse in Islamic literature, especially Islamic Indonesian children's literature which was marginalised in Indonesian literature history. The paper aimed to identify the system of exclusion or prohibition, restrictions to discourse and genealogical aesthetics of Islamic children's literature. The data utilised were various discourses available in Indonesian literature, aesthetics in the history of the literature mentioned, Indonesian literary experts and critics'opinions, and different information related to the topic. Data interpretation was executed based on the strategy introduced by Michel Foucault on discourse and power. Results showed that the discourse of Islamic literary aesthetics was deliberately eliminated during the New Order era because it was believed to be a part of the right-wing political power apparatus. That exclusion was carried out with restrictions and prohibitions by highlighting the aesthetics of development and modernity as the dominant aesthetic discourse in Indonesian literature, such as universal humanism. The history of aesthetic discourse in Islamic literature, including Islamic children's literature, appeared significantly during the Post-Reformation era due to the New Order's collapse. Hence aesthetic discourses that emerged afterwards were highly diverse and on par with other genres.
\end{abstract}

Keywords: Islamic literary aesthetic discourse, children's literature, Indonesian literary history. 


\begin{abstract}
Abstrak
Penelitian ini memfokuskan pada penyebaran wacana estetika sastera Islam terutama pada sastera kanak-kanak yang diketepikan daripada sejarah sastera Indonesia. Tujuannya adalah untuk mengetahui sistem penyisihan atau larangan, sekatan wacana, dan genealogis estetika sastera Islam untuk kanak-kanak. Data yang digunakan adalah wacana-wacana yang berada dalam sastera Indonesia, estetika dalam sejarah sastera Indonesia, pendapat ahli dan pengkritik sastera Indonesia, dan pelbagai informasi yang berkaitan topik penelitian. Teknik interpretasi data dilakukan dengan pangkalan pada strategi yang diperkenalkan oleh Michel Foucault tentang wacana dan kuasa. Hasil yang diperoleh menunjukkan bahwa wacana estetika sastera Islam kanak-kanak sengaja disingkirkan daripada Orde Baru kerana dianggap sebagai sebahagian daripada aparatus kekuatan politik sayap kanan. Penyingkiran itu dilakukan dengan pembatasan dan larangan dengan memunculkan estetika pembangunan dan kemodenan sebagai wacana estetika yang dominan dalam sastera Indonesia, seperti humanisme universal. Sejarah wacana estetika sastera Islam termasuk sastera kanak-kanak mengalami kemunculan yang signifikan dalam era Pasca Reformasi akibat runtuhnya kuasa Orde Baru sehingga wacana estetika yang muncul ketika itu adalah sangat pelbagai dan setanding genre lain.
\end{abstract}

Kata Kunci: wacana estetika sastera Islam, sastera kanak-kanak, sejarah sastera Indonesia.

\title{
Pendahuluan
}

Kehadiran estetika Islam terutama dalam sastera kanak-kanak Indonesia kurang mendapat perhatian dalam sejarah sastera Indonesia. Wacana estetika sastera Islam untuk kanak-kanak hampir tidak ditemui dalam perbahasan atau kajian kritikan sastera Indonesia. Namun, kehadiran wacana estetika Islam dalam sastera kanak-kanak Indonesia merupakan satu realiti yang tidak harus diabaikan. Fakta ini terdapat dalam beberapa buku bacaan kanak-kanak yang berkonsepkan keislaman. Keadaan ini menjadi satu kewajaran kerana masyarakat Indonesia merupakan majoriti Islam yang terbesar di dunia. Persoalan yang menarik adalah "mengapa wacana estetika Islam untuk sastera kanak-kanak tidak pernah dibicarakan oleh para akademik atau pengkaji sastera Indonesia?" Sementara itu, estetika sastera Islam pada hakikatnya sudah ada sejak beradab-abad lampau, seperti dalam dunia Melayu pada era Hamzah Fansuri (Ahmad \& Hanafiah, 2019, p. 172).

Sementara itu, perbincangan mengenai estetika Islam dalam sastera Indonesia sendiri telah banyak dilakukan oleh ahli akademik atau pengkritik sastera. Pengkajian itu umumnya menelaah tata naratif teks sastera yang dianggap perwakilan sastera Islam yang dihubungkan dengan ajaran agama Islam. Hal ini dapat dilihat daripada penelitian seperti Isnaniah (2014) yang meneliti perwakilan ajaran Islam dalam karya-karya Habiburrahman el Shirazy, Wahyuningsih (Wahyuningsih, 2015) yang berpendapat tentang pesan dakwah dalam filem Ayat-ayat Cinta, dan lain-lain. Kedua-dua contoh pengkajian ini masih mengungkapkan bahwa teks sastera Islam diyakini memberikan manfaat pada pembaca dengan mesej dan perwakilan nilai-nilai keislaman yang ada dalam karya tersebut.

Sementara itu, kajian sastera atau estetika Islam juga difokuskan sebagai satu pergerakan sosial. Sebagai contoh, kajian yang dilakukan oleh Salam menunjukkan bahwa pergerakan penciptaan sastera yang "bertema Islam" merupakan gerakan sosial dan budaya untuk menjadi pengimbang 
dan pertahanan atas wacana estetika yang dominan dalam sastera Indonesia di Yogyakarta (Salam, 2004). Andriani melihat ideologi tentang persekolahan atau pendidikan keagamaan Islam menjadi satu agen yang disebarkan melalui novel Negeri 5 Menara (Andriani, 2019). Dua penelitian ini memberikan petunjuk keberadaan sastera Islam atau estetika Islam membawa pengaruh yang cukup bermakna dalam lingkungan dan perubahan masyarakat sekitarnya.

Keempat-empat penelitian tersebut melihat estetika sastera Islam dalam sastera Indonesia sebagai sebahagian daripada estetika sastera Indonesia. Secara tidak langsung, wacana estetika Islam sememangnya wujud dan hadir dalam sastera Indonesia. Selanjutnya, penelitian yang berkaitan dengan genre sastera Islam kanak-kanak masih mengkaji persoalan tata naratif, nilai-nilai yang dihadirkan dalam teks, representasi gender dan lain-lain. Sebahagian fakta ini memberikan bukti bahwa kehadiran estetika sastera Islam terutama sastera kanak-kanak menjadi bahagian yang terasing atau tersingkir dalam wacana estetika. Bahkan, konsep sastera Islam sendiri juga masih dalam perdebatan para ahli sastera Indonesia (Kholil, 2011, Syaifudin, 2002).

Beberapa penelitian tersebut menunjukkan bahwa estetika sastera Islam atau sastera Islam kanak-kanak masih dalam perdebatan dan kehadirannya masih diragukan sebagai satu genre tersendiri. Keadaan ini membuktikan bahwa terdapat politik estetika atau wacana estetika yang dipolitikkan sehingga kehadirannya masih dalam perdebatan. Estetika sastera Islam kanak-kanak atau estetika Islam dibangun atau disingkirkan oleh kekuatan-kekuatan sosial. Hal ini sekaligus menimbulkan pertanyaan seperti apakah larangan-larangan yang ada untuk menyingkirkan estetika sastera Islam kanak-kanak dalam sejarah sastera Indonesia? Pertanyaan berikutnya adalah apakah mekanisme "penyisihan estetika sastera Islam kanak-kanak" dalam sejarah sastera Indonesia terutama era 1980-an sehingga era Reformasi? Dua pertanyaan tersebut mengimplikasikan pada genealogi wacana sastera Islam kanak-kanak.

Artikel ini berusaha membongkar konstruksi wacana estetika sastera Islam kanak-kanak yang disingkirkan oleh kekuatan-kekuatan sosial, terutama era Orde Baru. Meskipun disingkirkan oleh kekuatan sosial, pada hakikatnya, wacana yang lain turut berkonstribusi menyingkirkan estetika sastera Islam kanak-kanak. Wacana estetika yang dominan dalam sastera kanak-kanak Indonesia merupakan salah satu bahagian yang turut menyumbang dalam menyingkirkan estetika sastera kanak-kanak (sastera Islam). Oleh sebab itu, penyebaran wacana estetika menjadi bahagian yang perlu ditelusuri. Menurut Foucault (2012), wacana sering kali dihubungkan dengan kuasa dan pengetahuan. Beliau mengemukan bahwa kesatuan wacana selalu berhubungan dengan wacana yang lain, yang tidak ada akhirnya atau tidak terputus. Satu wacana adalah berkaitan dan berhubungan dengan wacana yang lain, sama ada menolak, menyokong, atau menyerupai wacanawacana yang lainnya.

Masyarakat memiliki produksi wacana yang terus diawasi, diorganisasi, dikawal dan diagihkan melalui berbagai-bagai prosedur (Faruk, 2012). Prosedur-prosedur wacana itu mengawasi kuasa atau risiko yang mungkin muncul untuk mendapatkan penguasaan atas sesuatu peristiwa, meskipun hanya suatu kebetulan. Salah satu yang wujud daripada keadaan itu adalah sistem penyisihan atau pelarangan. Sistem ini oleh Foucault diwujudkan melalui pelarangan yang saling berinteraksi, saling memperteguhkan, dan melengkapi. Larangan itu antaranya adalah larangan objektif yang bermaksud tidak semua orang memiliki autoriti untuk bersuara. Seterusnya adalah larangan kontekstual, yang bermaksud tidak semua orang bersuara mengenai sesuatu dalam konteks peristiwa tertentu. Sementara itu, larangan subjektif bermakna bahwa tidak semua orang 
boleh berbicara mengenai segala hal. Semua larangan ini berhubungan dengan kekuasaan dan pengetahuan.

Seterusnya yang timbul daripada hal itu adalah pemisahan dan penolakan. Hal ini memiliki tujuan agar gagasan mengenai sesuatu yang sah, benar, dan salah dapat dicapai dan dijadikan perkara rasmi. Lembaga kekuasaan sendiri memiliki sebuah kekuasaan yang melindungi dan menciptakan wacana, seperti lembaga penelitian, penerbit, subjek, perantara, lembaga negara, dan lain-lain. Mereka memiliki tugas yang sama, yakni mengatur tata laksana berbagai-bagai kekuasaan yang ada dalam wacana yang diciptakan. Lembaga ini berperanan dalam pengagihan dengan berdasarkan pada hirarki yang teratur (Foucault, 2008). Sementara itu, berbagai-bagai pihak memberikan batasan dan pihak yang berbeza memberikan aturan ke atas ekspresi atau produk kultural dan sosial, dalam konteks ini termasuk karya sastera atau estetika, yang berada dalam wilayah kekuasaannya.

Kekuasaan sendiri pada dasarnya memiliki hubungan yang saling mengatur dalam berbagaibagai wacana yang ada dalam lintasannya. Pada dasarnya, kekuasaan itu dapat melemahkan, menguatkan, mengagihkan, dan mengatur berbagai-bagai wacana yang ada. Kekuasaan itu boleh memberikan rangsangan terhadap kemunculan wacana yang baharu. Foucualt (2008) berpendapat bahwa wacana sendiri tidak terlepas daripada kekuasaan meskipun satu wacana dengan wacana lain bertentangan, tetepi memiliki satu kesatuan yang sama. Sementara itu, modal penyampai wacana dapat berasal daripada mana-mana sahaja, seperti siapa yang berbicara, pihak insititusional, dan posisi subjek yang bertindak (Foucault, 2012).

Selanjutnya, untuk mengetahui penyebaran wacana dan menganalisis wacana yang dominan atas suatu objek, hal yan pertama diungkapkan adalah kekuasaan yang berada dan mendominasi wacana tertentu. Subjekjuga memiliki strategi dalam mengukuhkan kekuasaan atas keberlangsungan subjek. Dengan kepelbagaian cara, subjek boleh menciptakan atau menerbitkan sesuatu. Wacana sendiri dapat berasal daripada berbagai-bagai realiti yang tidak bersifat tunggal. Wacana secara terus menerus berlangsung tanpa henti dan tersebar ke segala penjuru yang beraneka ragam.

\section{Metod Penelitian}

Objek formal penelitian ini adalah wacana estetika Islam dalam sastera Islam kanak-kanak Indonesia. Objek material untuk penelitian ini ialah sejarah sastera Indonesia period Orde Baru (1980-an). Data penelitian ini ialah informasi tentang sejarah sastera Indonesia, wacana estetika Islam dalam sejarah sastera Indonesia, idea atau gagasan tentang sejarah sastera Indonesia, dan berbagai-bagai pernyataan para pelaku atau ahli kesusasteraan Indonesa. Teknik interpretasi data dilakukan dengan mendasarkan pada tata laksana dari teori wacana Foucault. Faruk memperkenalkan beberapa langkah dalam teknik analisis data berdasarkan teori wacana Foucault, iaitu prinsip pembalikan, prinsip ketidaksinambungan, prinsip pengkhususan, dan prinsip luaran. Prinsip-prinsip tersebut dikelompokkan dalam dua analisis utama, iaitu analisis kritis (pelarangan, penyisihan, dan disiplin) (Faruk, 2012). Ia merupakan kawalan atas wacana dan analisis genealogis wacana. Analisis itu merupakan penentuan batas-batas wacana yang tersebar dengan wacana yang lain. 


\section{Hasil dan Pembahasan}

\section{"Estetika Pembangunan" sebagai Kewujudan Sistem Penyisihan}

Sebagaimana yang disebutkan, sistem penyisihan ini diwujudkan melalui larangan terhadap konsep estetika dalam dunia sastera, terutama sastera kanak-kanak. Tema-tema sastera Islam kanak-kanak pada era 1980-an pada dasarnya tidak hanya berhubungan dengan dunia kanak-kanak secara keseluruhan. Hal ini mempunyai hubungan secara khusus dengan estetika yang dikembangkan oleh Orde Baru. Sastera atau estetika sastera pada masa ini cenderung bersifat "materialisme humanis" yang menekankan pada subjek yang memihak pada kepentingan pemerintah, iaitu konsep "pembangunan" melalui Repelita dan pelaksanaan Pancasila dan Undang-undang Dasar 1945. Selain itu, konsep modernisasi masyarakat juga turut memberikan sumbangan pada dasar estetika oleh negara. Hal ini berkesan pada estetika yang bersifat komunisme atau materialisme sosialis dan estetika Islam sebagai gerakan sosial yang dilarang.

Keadaan ini disebabkan sastera Islam kanak-kanak atau estetika Islam yang cenderung dianggap sebagai gerakan politik sayap kanan. Larangan terhadap estetika Islam pada masa ini cenderung dialihkan pada sikap bahwa Islam merupakan kekuatan politik kanan yang "sangat berbahaya", berikutan dengan perjuangan Islam pada era kolonial Belanda dan Jepun hingga gerakan Islam era Soekarno. Pada masa pemerintahan Soekarno, parti Islam juga memiliki lembaga kebudayaan sebagai salah satu pusat gerakan massa (Chisaan, 2012). Sebagai akibatnya, estetika yang bernafaskan keislaman sebagai gerakan sosial politik dilarang dengan menghadirkan wacana tandingan dalam dunia kesasteraaan, terutama sastera kanak-kanak. Larangan itu juga dilanjutkan dengan sistem penyisihan yang merupakan larangan secara objektif, konstekstual, dan subjektif dalam kesastaraan Indonesia secara keseluruhan.

Larangan secara objektif itu diwujudkan dengan membangun konsep estetika dalam dunia sastera kanak-kanak. Langkah itu diwujudkan dalam penerbitan karya sastera kanak-kanak versi negara melalui Balai Pustaka. Autoriti dalam dunia estetika sastera dikembangkan melalui lembaga-lembaga negara seperti Pusat Bahasa, Balai Pustaka (warisan kolonial), penghargaan sastera oleh negara, sekolah (melalui guru), hingga para pengkritik yang bergabung dalam estetika "materialisme humanis", seperti dalam majalah sastera Horizon dan lain-lain. Mereka mereka bentuk estetika yang layak disebut sebagai kesasteraan atau sastera, yang mempunyai kesan pada sastera kanak-kanak. Penganugerahan atau hadiah sastera dapat dipandang sebagai sebahagian daripada praktik politik wacana (Susanto, 2015).

Larangan konstektual ini diwujudkan melalui pihak yang berautoriti dalam membincangkan wacana estetika atau sastera, terutama sastera kanak-kanak. Pihak yang berhak membicarakan dan mendefinisikan sastera kanak-kanak dalam konteks ini lebih ditujukan pada guru dan sekolah. Mereka dipandang sebagai pihak yang mempunyai kompetensi dan kemampuan dalam membincangkan sastera kanak-kanak. Sebagai contoh, para guru mengikuti sayembara penulisan bacaan kanak-kanak atau sastera kanak-kanak yang diterbitkan oleh Balai Pustaka (Partiningsih, 2015). Selain itu, lembaga pemerintah lainnya yang mengurus isu berkaitan bahasa dan pendidikan juga turut membantu aktivit--aktiviti para guru sebagai ahli sastera, terutama sastera kanak-kanak. Hasil daripada pendidikan tersebut dapat dilihat dalam buku pelajaran Bahasa Indonesia dan sekaligus buku bacaan untuk kanak-kanak seperti yang diterbitkan oleh Balai Pustaka melalui sayembara. Buku-buku tersebut tentu saja sebagai sebahagian lanjutan wacana versi Orde Baru 
untuk menekankan sastera Islam kanak-kanak (Susanto \& Wati, 2019).

Larangan yang berikutnya, iaitu larangan subjektif, wujud daripada kehadiran negara dalam dunia sastera kanak-kanak. Ianya berkaitan dengan pihak yang berhak menciptakan wacana sastera kanak-kanak yang bersesuaian dengan visi dan cita-cita ideologis. Di samping itu, lembaga yang lain juga turut menyetujui larangan subjektif ini. Misalnya, sastera kanak-kanak yang diterbitkan oleh Gramedia dan Tiga Serangkai. Fakta itu dapat dilihat daripada buku yang berjudul Meniti Kehidupan (Tipan) (1985), terbitan Tiga Serangkai, karya Punk Pribadi yang berpendapat tentang ajakan bahwa Pancasila memiliki peranan yang penting dalam membina kehidupan. Gagasan yang demikian juga diikuti oleh buku lain seperti Pengusaha Kecil (1985), Si Anak Piatu (1985), Anak Panti Asuhan (1986), Lawa Ijo (1984), dan lain-lain. Sementara itu, Gramedia mengambil jalan yang agak berbeza dengan menghadirkan buku-buku terjemahan sastera kanak-kanak barat, terutama dari Eropah dan Amerika, seperti Petualangan Tom Sawyer dan karya-karya Enid Blyton. Kedua-dua penerbit ini tentu sahaja tidak berani menerbitkan estetika sastera Islam kanak-kanak sebagai gerakan sosial kanak-kanak.

Berdasarkan hal itu, sastera kanak-kanak yang muncul pada era ini adalah sastera kanakkanak versi Balai Pustaka, Tiga Serangkai, dan Gramedia. Sastera kanak-kanak versi Balai Pustaka merupakan milik negara atau Orde Baru, yang diikuti oleh kedua-dua penerbit tersebut atau lembaga yang lain. Sastera kanak-kanak Balai Pustaka sebagai sebahagian atau pewujudan larangan merupakan contoh daripada sastera kanak-kanak yang harus dikembangkan. Isi atau tata naratif daripada sastera kanak-kanak versi negara ini merupakan lanjutan daripada dasar atas penguasaan memori kanak-kanak Indonesia. Ianya adalah sebahagian daripada penanaman ideologis keindonesiaan milik Orde Baru. Sebagai contoh, sastera kanak-kanak versi negara ini membangunkan tema-tema seperti peranan negara dalam membantu pendidikan untuk keluarga yang miskin (Bunga-Bunga Hari Esok karya Sasmito, 1983 atau Penyelamat Desa karya Yacob, 1982), kemandirian ekonomi keluarga (Pandu Cucu Seorang Pejuang karya Thachir, 1986), peranan pemuda dalam pembangunan (Bunga-Bunga Hari Esok karya Sasmito,1983), pembangunan kemudahan dan prasarana (Taman Sekolah karya Manto, 1983), dan nilai-nilai Pancasila hingga semangat perjuangan pahlawan (Partiningsih, 2015).

Tema-tema itu terhasil daripada sistem penyisihan, iaitu usaha negara dalam mengendalikan dan membangunkan wacana bagi dunia dan fikiran kanak-kanak. Tujuannya adalah untuk menguasai fikiran kanak-kanak. Secara umum, Orde Baru mengeluarkan konsep "estetika pembangunan" dalam sastera kanak-kanak waktu itu. Hal ini dengan alasan bahwa "estetika pembangunan" merupakan sebahagian daripada usaha Orde Baru untuk melakukan tindakan penekanan terhadap estetika Islam. Pengaturan, pengekangan, dan batasan-batasan yang dikeluarkan Orde Baru sebagai akibatnya memunculkan sastera kanak-kanak yang berestetika Islam dengan pandangan dan isi yang "sangat jauh" daripada dunia kanak-kanak. Hal ini sebagai contoh adalah kisah tentang Neraka dan Surga atau kisah para wali penyebar Agama Islam di Jawa hingga kisah para nabi dan rasul atau tokoh Islam yang lain.

Penekanan estetika ini walau bagaimanapun tidak begitu berhasil dalam menekan jumlah bacaan atau keterbacaan kanak-kanak Indonesia dalam menggunakan sastera yang berbeza daripada konsep "estetika pembangunan" Orde Baru. Penerbitan karya terjemahan seperti yang dikemukakan sebelumnya dapat menjadi salah satu contoh, seperti Alice in Wonderland atau Pinokio. Selain itu, kemunculan sastera kanak-kanak tradisional seperti kisah Bawang Merah 
Bawang Putih, Timun Emas, hingga Dayang Sumbi, dan lain-lain juga tidak mampu menekan keterbacaan golongan kanak-kanak pada sastera kanak-kanak. Nilai-nilai atau gagasan "estetika pembangunan" tidak mampu disisipkan dalam cerita kanak-kanak. Namun, sangat dimungkinkan, projek menghasilkan buku menyisipkan cerita tradisional untuk kanak-kanak sebagai sebahagian daripada penekanan atas nama "estetika pembangunan".

Kemunculan sastera kanak-kanak Islam pada era Orde Baru atau 1980-an merupakan sastera kanak-kanak yang dibungkam melalui estetika pembangunan. Bahkan, dalam sistem penyisihan, para pengkritik sastera tidak melihat bahawa sastera kanak-kanak sebagai "sastera" yang layak dipelajari dan diteliti secara akademik. Hal ini terbukti daripada tulisan-tulisan para akademi dan pengkritik sastera pada masa itu hingga sastera kanak-kanak cenderung tidak dianggap sebagai "kajian yang ilmiah atau layak diperhatikan". Melalui wacana pembungkam dan peniadaan sastera kanak-kanak dalam dunia estetika sastera Indonesia, kehadiran cerita Surga dan Neraka atau cerita para nabi hingga para tokoh Islam cenderung hadir dalam dunianya sendiri. Hal ini bermaksud, pembaca atau konsumer, tampilan naratif, reka bentuk material buku, hingga sistem pengagihan "terasing" bila dibandingkan dengan sastera versi Balai Pustaka, Gramedia dan Tiga Serangkai. Sastera tersebut atau karya sastera tersebut merupakan sastera yang hadir dan disingkirkan disebabkan secara nyata tidak dipelajari dan diajarkan secara rasmi oleh lembaga milik negara seperti dalam lembaga pendidikan, misal sekolah atau universiti.

\section{Disiplin dan Pembatasan Sastera Anak Islami}

Wacana estetika sastera Islam kanak-kanak memang tidak boleh dipisahkan daripada estetika sastera pada umumnya. Konsep disiplin dan pembatasan ini memanfaatkan kekuatan dan politik kebudayaan pada masanya. Melalui slogan "identitas nasional" yang bertumpu pada gagasan estetika humanisme universal seperti dalam Manikebu (Manifesto Kebudayaan, 1960an), kekuasaan Orde Baru membangun sebuah konsep tentang disiplin dan pembatasan. Hal ini mempunyai kaitan dengan estetika Lesbumi (Lembaga Seniman Muslim Indonesia, 1960-an) atau Masbi (Musyawarah Seniman Budayawan Indonesia, 1960-an) yang menjadi sebahagian daripada parti sayap kanan ketika era Orde Lama berkuasa (Susanto, 2018). Hal ini sekaligus menunjukkan bahwa perbincangan mengenai estetika Islam selalu dikaitkan dengan kecenderungan sifat 'pemberontakan". Estetika Islam hanya boleh digunakan dalam konteks humanisme universal seperti meningkatkan hubungan manusia dengan Tuhan atau kerohanian peribadi. Hal ini sangat wajar memandangkan Soeharto atau Orde Baru sangat takut dan khuatir dengan kekuatan Islam sehingga menubuhkan lembaga kebudayaan untuk tujuan tersebut (Anderson, 1990).

Tatatertib dalam estetika sastera kanak-kanak Islam ini diwujudkan bukan hanya di sekolah melalui guru dan bahan bacaan. Namun, disiplin ini diwujudkan melalui estetika sastera secara umum. Posisi yang bersifat "a-politis" dalam konteks estetika sastera diwujudkan dalam konsep yang dibawa oleh kelompok humanisme universal. Kesenian atau sastera ini dipandang sebagai hiburan yang membawa kemajuan dari aspek akhlak dan kerohanian (Jones, 2015). Sastera yang dianggap sebagai sebahagian daripada gerakan sosial politik adalah dilarang dan tabu untuk dibincangkan. Hal ini boleh dilihat berdasarkan kes-kes buku-buku atau naskah dari Pramoedya Ananta Toer, yang menjadi simbol dari tentangan ketika itu (Toer, 1981). Perkara ini sudah pastinya 
tercetus pada sastera Islam. Sebagai akibatnya, sastera Islam mengubah dirinya atau keberadaanya dalam konteks sastera profetik atau sastera sufistik (Susanto \& Wati, 2019). Keadaan ini pada hakikatnya sebagai akibat pendisiplinan atau pembatasan konsep sastera, yang berakibat pada estetika Islam.

Daripada hal tersebut, kewujudan sastera Islam kanak-kanak juga mengikuti gagasan estetika sastera Indonesia pada umumnya. Disiplin dan pembatasan itu dilanjutkan dengan memunculkan wacana "estetika pembangunan" sebagai wacana tandingan atas kemunculan estetika Islam. Identiti nasional dan kebudayaan daerah, terutama Jawa, menjadi bahagian yang terus menerus dilaungkan untuk menghalang "identiti keislaman". Konsep nasionalisme, moderniti, dan Pancasila menjadi alat kekuasaan Orde Baru dalam menekan kehadiran sastera Islam. Estetika Islam "didiamkan", terutama sastera kanak-kanak Islam, era 1980-an pada hakikatnya selalu dihubungkan dengan sifat negatif, iaitu pemberontakan. Sebagai akibatnya, estetika Islam berada dalam kecenderungan untuk membawa sastera atau estetika pada domain sufistik ataupun mistisme (Simuh, 1995).

Sebagai contoh yang lain daripada sistem tatatertib dan pembatasan estetika ini adalah penganugerahan sastera. Contohnya adalah Hadiah Sastera Majalah Horison dan Hadiah Sastera Pusat Pembinaan dan Pengembangan Bahasa. Kedua-dua lembaga ini memberikan kriteria tertentu dalam anugerah atau hadiah yang diberikan. Kencenderungan estetika yang digunakan dilihat daripada para pemenang dan dewan juri hingga penyelenggaranya. Kesemuanya merupakan sebahagian alat kekuasaan yang mengatur gagasan wacana estetika. Dari sekian pengarang dan karya sastera yang ada, karya-karya yang bersifat Islam dan sosialisme tidak ada yang menang bahkan kecenderungan dilarang hadir atau tidak ada. Keadaan ini dapat dicontohkan daripada larangan karya yang ditulis oleh para sasterawan yang terlibat atau bergabung dalam Lembaga Kebudayaan Rakyat atau Lekra, yang berhaluan realisme-sosialis. Bahkan, kecenderungan peristiwa Lekra versus Manikebu diungkapkan untuk menghalang amalan politik dalam estetika (Ismail \& Moeljanto, 1995).

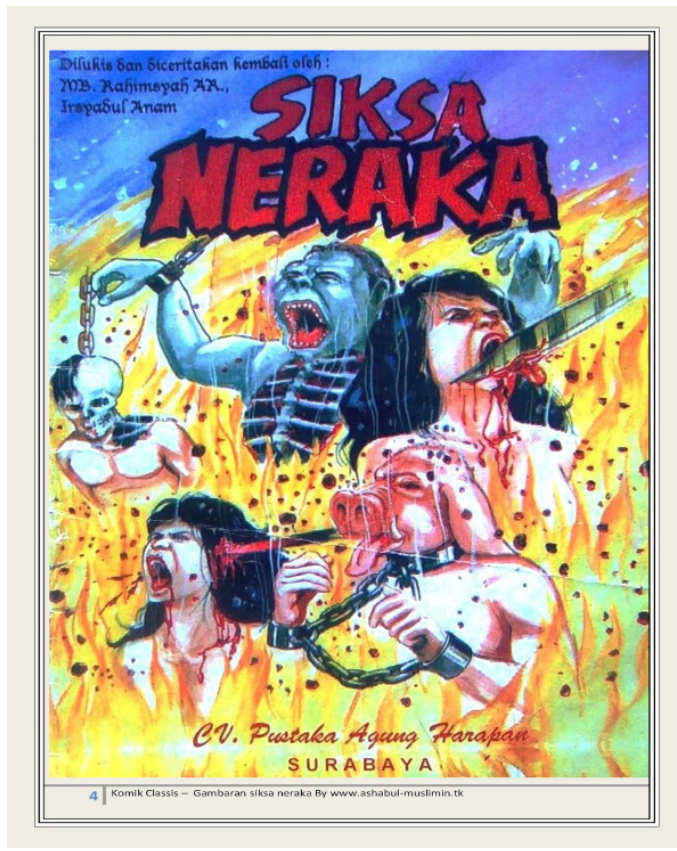

Gambar 1: Sampul buku Siksa Neraka 
Gambar 1 merupakan salah satu contoh dari genre cerita Islam kanak-kanak pada era Orde Baru. Kemunculannya merupakan akibat daripada tatatertib dan pembatasan dalam sastera kanakkanak. Estetika Islam masih dipandang sebagai estetika pemberontakan yang berbahaya. Sebagai akibatnya, sastera kanak-kanak yang bertemakan Islam hanya boleh digunakan atau diajarkan di sekolah melalui pendidikan agama. Akhirnya, sastera Islam kanak-kanak dibuat dalam bentuk formal yang "menghancurkan" identiti estetikanya. Ia hadir di luar narasi wacana besar yang dinarasikan oleh kekuasaan dan sastera dalam era Orde Baru. D.H Hill mengatakan bahwa kebebasan eskspresi estetika ketika Orde Baru selalu dihubungkan dengan ancaman keterlibatan seniman atau karyawan seni sayap kiri (sosialisme-komunisme) dan pengurusan lembaga kebudayaan yang tetap dalam kawalan negara. Hal ini sebagaimana yang terjadi dalam konteks pembentukan Taman Ismail Marzuki atau TIM (Hill, 1993).

Contoh kes pembentukan TIM tersebut merupakan wujud daripada reka bentuk dan campur tangan kekuasaan negara dengan turut menarasikan gagasan estetika pembangunan melalui larangan terhadap sayap kiri dan sayap kanan (gerakan Islam). Estetika yang dikembangkan tersebut tidak dilakukan serta merta oleh keseluruhan penulis sastera. Sebagai contoh, kemunculan gerakan sastera kontekstual atau Gerakan Seni Baru (Foulcher, 1987, Supangkat, 1990) memberikan tanda-tanda bahawa gerakan estetika humanisme universal sebagai sebahagian daripada disiplin dan pembatasan estetika yang semakin dipersoalkan oleh para pelaku seni dan dunia sastera.

Pendisiplinan dan pembatasan yang dilakukan oleh Orde Baru tersebut memunculkan satu estetika Islam dalam sastera Indonesia. Meskipun estetika Islam ini tidak terkait secara formal dalam konteks sastera Islam kanak-kanak, kehadirannya dapat menjadi perbandingan atau rujukan daripada perkembangan genre yang membawa estetika Islam sebagai satu wacana estetik dalam sastera Indonesia. Sebagai contoh, kemunculan sastera sufi yang dipandang sebagai penentangan atau wacana perjuangan terhadap estetika yang berkembang dan menguasai sastera Indonesia pada masa itu. Hal ini sebagai mana diungkapkan oleh Salam (2004) mengenai kewujudan sastera sufi di Yogyakarta. Kehadiran karya-karya daripada Emha Ainun Najib, Abidah El Khalieqy, Mustafa W Hasyim, Amin Wangsitalaja, dan lain-lain dipandang sebagai perwakilan sastera Islam pada masa Orde Baru. Kehadirannya sering dipandang sebagai gerakan alternatif sastera Indonesia Orde Baru, yang sama dengan perjuangannya.

Dalam estetika sastera Islam kanak-kanak, disiplin itu dilakukan melalui usaha bahwa ideologi merupakan amalan negara sehingga sastera tidak atau dilarang berpolitik dan berideologi. Hal ini dilakukan dengan cara mengembangkan wacana sastera kanak-kanak yang berorientasi pada wacana pembangunan negara dan modernisasi. Melalui contoh pada perkembangan modernisasi negara barat, wacana yang dimunculkan adalah keterbelakangan negara. Oleh sebab itu, sastera, khususnya, sastera Islam kanak-kanak harus mengembangkan gagasan yang sedemikian. Hal ini sebagaimana diambil alih peranannya oleh Balai Pustaka dan guru-guru di sekolah

Pembatasan dan displin ini tidak hanya diwujudkan dengan memunculkan wacana estetika pembangunan dan modernisasi. Namun, displin itu dilakukan melalui sekolah-sekolah dengan memperkenalkan konsep seorang Islam atau muslim Pancasila. Muslim Pascasila ini pada umumnya ditujukan untuk membendung gerakan-gerakan keislaman, seperti Muhamdiyah atau Nahdhatul Ulama, yang cenderung dipandang oleh Orde Baru sebagai kekuatan politik yang berbahaya. Mereka dipandang sebagai sebahagian daripada sayap kanan. Gerakan muslim Pancasila ini berimbas pada domain atau ranah estetika. Sastera yang dikembangkan adalah sastera yang sesuai 
dengan peraturan interpretasi Pancasila Orde Baru. Hal ini memberi kesan kepada beberapa sasterawan yang ditahan dan dipenjara oleh Orde Baru kerana dianggap melakukan penentangan secara simbolik. Sastera Islam kanak-kanak wujud dalam bentuk dan ruang yang terasing. Namun hakikatnya, dalam persekolahan atau pendidikan Islam, sastera Islam kanak-kanak ini berkembang dalam bentuk tradisi persekolahan melalui cerita lisan dan yang serupa dengannya.

\section{Genealogis Wacana Sastera Islam Kanak-kanak}

Foucault mengemukakan bahwa kekuasaan itu ada di mana-mana dan meluaskan dirinya. Kekuasaan dipandang sebagai gandingan yang bertumpu pada mobiliti atau perpindahan. Kekuasaan itu sendiri adalah sebuah identiti yang diberikan kepada suatu situasi strategi yang rumit dalam masyarakat. Genealogis sebuah wacana meluaskan wacana dalam bentuk yang tidak tunggal, tidak terpusat, dan menyebar ke berbagai-bagai pihak (Foucault, 2012). Sastera Islam kanak-kanak juga tidak terlepas daripada salasilah kehadirannya dalam konteks wacana sastara kanak-kanak yang lain. Oleh sebab itu, penyebaran wacana sastera kanak-kanak dalam konteks sastera Indonesia perlu dilihat sebagai sebahagian daripada persaingan wacana kerana wacana mampu membangun kemajuan sosial.

Genealogis sastera Islam kanak-kanak memang tidak boleh dilepaskan daripada sastera kanak-kanak bukan Islam. Pertama, adalah sastera kanak-kanak Balai Pustaka yang merupakan sastera kanak-kanak versi negara. Ia menerbitkan sastera kanak-kanak dengan tema pembangunan dan pemodenan yang bertumpu pada Pancasila. Akibatnya, tema-tema yang ditulis adalah tema pembangunan desa atau negara. Sebagai contoh, tema seperti pendidikan bagi golongan kanakkanak miskin, kemandirian ekonomi keluarga, pemuda dalam pembangunan, hingga nilai-nilai Pancasila. Sastera kanak-kanak ini tersebar melalui projek negara dan dilaksanakan di sekolahsekolah seluruh Indonesia. Sekolah yang difokuskan adalah sekolah negara atau sekolah kerajaan. Sebagai akibatnya, Balai Pustaka atau negara tidak menerbitkan sastera Islam kanak-kanak.

Hal kedua adalah sastera kanak-kanak yang diterbitkan oleh Pustaka Jaya. Pada era 19801990-an, karya sastera kanak-kanak yang diterbitkan oleh Pustaka Jaya ini masih menyerupai dengan karya sastera Balai Pustaka. Pustaka Jaya jarang atau boleh dikatakan hampir tidak ada penerbitan karya sastera Islam kanak-kanak. Sastera kanak-anak Pustaka Jaya lebih menonjolkan pada kehidupan kanak-kanak, misalnya melalui permainan golongan kanak-kanak, cita-cita, keinginan dan permasalahan dalam dunia mereka. Contoh karya sastera kanak-kanak era Balai Pustaka adalah Anak Dusun (1977) karya Mansur Samin, Terpikat Gatotkaca (1975) karya Min Resmana, dan lain-lain. Selanjutnya hal yang ketiga adalah estetika yang dikembangkan oleh Tiga Serangkai. Tema yang dikembangkan dalam sastera kanak-kanak terbitan Tiga Serangkai adalah pengalaman kanak-kanak di kawasan kampung atau pinggiran, cerita sejarah, pengembaraan dan permainan kanak-kanak. Contoh karya sastera kanak-kanak ini antaranya ialah Balada Pengarang Muda (Balada) (1982) karya Punk Pribadi, Si Anak Piatu (1985) karya Punk Pribadi, Anak Panti Asuhan (1987) karya Punk Pribadi, dan lain-lain. Pustaka Jaya dan Tiga Serangkai tidak "bermain" dalam estetika Islam memandangkan hal ini akan disebabkan oleh larangan dan peringatan daripada pemerintah Orde Baru.

Selain itu, Gramedia lebih "bermain” pada sastera terjemahan untuk sastera kanak-kanak. Hal ini menyokong konsep estetika modernisasi atau pembangunan yang berpusat pada khazanah 
kebudayaan Eropah. Meskipun demikian,Gramedia juga membuat karya sastera kanak-kanak oleh pengarang Indonesia. Sebagai contoh, Djoko Leleno yang menulis siri Astrid, seperti Astrid di Palungloro (1982), Astrid Duel dengan Dukun (1985), Astrid Shooting di Pulau Bencana (1985) dan lain-lain. Selain Djoko Lelono, ada pengarang sastera kanak-kanak yang lain seperti Bung Smas dengan siri Noni, yang terdiri daripada Hantu Penculik (1983), Pelukis Misterius (1983), Empat Wajah Godek (1985), Komplotan Pencuri Berlian (1985) dan lain-lain. Karya-karya tersebut mengambil jalan yang berbeza dengan estetika Balai Pustaka atau estetika sastera kanakkanak ynag dikembangkan oleh Orde Baru. Hal ini seakan memberikan petunjuk bahwa Gramedia bermain dengan aspek komersial dan ideologi.

Genealogis estetika sastera Islam kanak-kanak dalam sastera Indonesia tidak begitu menonjol dalam era kolonial Belanda. Bacaan kanak-kanak yang muncul adalah bacaan yang disesuaikan dengan estetika kolonial. Sebagai contoh, bacaan kanak-kanak yang diterbitkan oleh misi agama Kristian atau mubaligh dari Eropah. Antara bahan bacaannya adalah kitab suci Injil yang digunakan di sekolah kolonial. Contoh yang lain ialah Penghidoepan Toehan Isa bagi AnakAnak; Ditjeritakan di dalam 52 Pasal (1923) oleh Mill Durff atau karya yang lain seperti Tjerita Peri Kehidoepan Santoo Tarcisioes Pelindoeng Anak-Anak jang Soedah Menjamboet Sacramen Mahakoedoes dan Soerat Santoo Bapa Pioes X, ja'ni Perintah dari hal 'oemoer jang Patoet kepada anak-anak jang Menjamboet Sacramen Mahakoedoes pada Pertama Kalinja. Teks-teks seperti ini umumnya diterbitkan oleh penerbit swasta Belanda yang mendukung misi peradaban kolonial.

Penerbitan teks-teks atau karya sastera kanak-kanak dalam era kolonial sememangnya diusahakan untuk menyokong kekuasaan kolonial Belanda. Hal ini mengakibatkan sastera Islam kanak-kanak dihapuskan dan tidak dijadikan sebagai bacaan kanak-kanak kolonial. Kekosongan bacaan kanak-kanak ini diisi oleh penerbit swasta milik pendakwah/mubaligh dan penerbit swasta peranakan Cina-Indonesia. Selain itu, pemerintah kolonial Belanda membentuk Balai Pustaka sebagai cara membangunkan estetika sastera yang merangkumi sastera kanak-kanak dan bacaan untuk golongan kecil tersebut. Balai Pustaka pada era kolonial (1920-an) menerbitkan karya sastera kanak-kanak yang bias pada kekuasaan atau bias pada kolonial (Jedamski, 1992). Hal ini mengembalikan isu tradisionalisme pada kerajaan di Nusantara, terutama Jawa, agar sifat dan hasrat memberontak masyarakat Islam pribumi dapat dikawal. Karya-karya itu antaranya adalah Petroek Dados Ratoe (1914), Bijoeng Koewoelan (1913), Tjangkriman Basa Djawa nganggo Tembang (1912), Hikajat Pelanduk Djinaka (1914), dan lain-lain. Terjemahan sastera barat untuk kanakkanak (Eropah) juga diperkenalkan oleh Balai Pustaka seperti Pinokio (1931), Putri Tidur (1925), Kanak-Kanak Berkeliling Doenia Diongkosi Surat Kabar (1938) dan lain-lain (Christantiowati, 1996).

Ketika memasuki zaman penjajahan Jepun (1942-1945), sastera Islam kanak-kanak tidak menunjukkan kewujudannya. Sastera kanak-kanak pada masa itu adalah sastera yang mendukung propaganda kolonialisme Jepun di Indonesia. Melalui lembaga Kokumin Tosyokyoku Balai Pustaka, pemerintah kolonial Jepun setidak-tidaknya menerbitkan bacaan kanak-kanak untuk sekolah-sekolah, seperti Matahari Terbit (1943), Kardi lan Kantjane (1942), dan lain-lain. Sementara itu, estetika yang diperkenalkan oleh pemerintah kolonial Belanda juga dilarang. Hal ini dapat dilihat pada larangan cerita kanak-kanak yang berjudul Mengelilingi Doenia dalam 80 Hari karya Jules Verne, Kembar Enam karya C. Joh. Kiebviet dan lain-lain. 
Kehadiran sastera Islam kanak-kanak semasa revolusi Indonesia pastinya bersekutu dengan kecenderungan politik Indonesia. Sebagai contoh adalah Partai Nahdatul Ulama dan Partai Masyumi yang sama-sama memiliki lembaga kebudayaan Islam. Kedua-dua parti Islam ini menjadi sebahagian daripada keberlangsungan estetika Islam. Namun setelah tumbangnya revolusi ini, estetika Islam oleh Orde Baru dikenali sebagai gerakan sayap kanan atau politik sayap kanan yang mengancam kekuasaan Orde Baru. Sebagai akibatnya, estetika Islam atau sastera Islam kanakkanak dilarang, didisiplinkan, dan disisihkan menjadi estetika yang "didiamkan" dan "dilarang".

Memasuki era Reformasi atau pasca 1998, kebebasan bereskspresi menjadi semangat zaman ini sehingga luahan kultural dan ideologis dibenarkan asalkan tidak bertentangan dengan undangundang negara. Sebagai akibatnya, estetika sastera Islam kanak-kanak dan estetika Islam pada umumnya menunjukkan kewujudannya melalui berbagai-bagai gerakan sosial hingga politik maupun ideologis keislaman. Bacaan kanak-kanak atau sastera kanak-kanak dalam masa ini menunjukkan keragaman. Wacana sastera Islam kanak-kanak ini diwujudkan dalam penerbitan dengan jumlah yang sangat banyak dan membawa konsep-konsep keislaman yang beragam. Hal ini sebagai contohnya adalah penerbitan sastera Islam kanak-kanak yang dilakukan oleh Mitra Bocah Muslim, Daar Mizan, dan lain-lain. Keragaman konsep Islam itu sendiri hakikatnya mencerminkan keragaman asas keislaman dalam sastera Indonesia.

Secara umum, genealogis sastera Islam kanak-kanak dalam sastera Indonesia tidak terlepas daripada kekuatan-kekuatan sosial dan ideologis yang membentuknya. Estetika sastera Islam kanak-kanak dalam paparan tersebut menunjukkan bahwa sastera Islam disingkirkan oleh kekuatan politik melalui disiplin dan larangan. Hal itu diwujudkan melalui pewujudan wacana sastera kanakkanak yang berestetika pembangunan dan gagasan "kemajuan zaman" atau moderniti. Melalui pelabelan, sastera Islam kanak-kanak dipandang sastera yang bersekutu dengan kekuatan politik sayap kanan, ideologi pemberontakan, dan berada dalam ranah tradisionalisme atau anti kemajuan. Ianya berada dalam dunia tradisional yang hanya boleh mempersoalkan hubungan manusia dengan Tuhan dan tidak boleh untuk turut memikirkan perubahan masyarakat. Gagasan ini merupakan konstruksi kemodernan yang dibangunkan oleh estetika bukan atau non-Islam.

\section{Kesimpulan}

Wacana estetika sastera Islam, terutama estetika sastera Islam kanak-kanak dalam zaman Orde Baru (1980-an) sengaja disingkirkan karena dianggap sebagai sebahagian daripada politik sayap kanan yang juga menentang kekuasaan negara. Penyingkiran itu dilakukan dengan membangunkan wacana tandingan, iaitu wacana estetika pembangunan dan moderniti. Sebagai akibatnya, estetika sastera yang dominan dalam sejarah sastera Indonesia adalah estetika leluhur daripada estetika pembangunan dan moderniti, iaitu estetika humanisme universal, materialisme dan lokaliti. Penyingkiran itu dilakukan dengan cara membatasi dan melakukan larangan secara nyata dan tidak kelihatan. Hal ini dilakukan dengan menerbitkan buku bacaan kanak-kanak yang sesuai dengan visi daripada kekuasaan Orde Baru. Namun, sastera Islam kanak-kanak tetap hadir dalam bentuknya yang mendekonstruksi dirinya sendiri. 


\section{Rujukan}

Ahmad, N. A., \& Hanafiah, H. A. M. (2019). Pemikiran Islam dalam konteks sosioekonomi dalam Kumpulan Cerpen Cahaya Pelita Nurani (Islamic Thought in the Context of Socioeconomics in the Short Story Cahaya Pelita Nurani). Jurnal Pengajian Melayu/ Journal of Malay Studies (JOMAS), 30(1), 167-187.

Anderson, B. R. O. (1990). Old State, new society: Indonesia's new order in comperative historical perspective. In B. R. . Anderson (Ed.), Language and Power, Exploring political culture in Indonesia (pp. 94-120). Ithaca, New York: Cornell University Press.

Andriani, D. (2019). Ideologi pesantren sebagai agent of change pada Novel Negeri 5 Menara karya Ahmad Fuadi: Sebuah analisis wacana kritis. Linguista Jurnal Ilmiah Bahasa Sastra dan Pembelajarannya, 3(2), 133.

Chisaan, C. (2012). In search of an Indonesian Islamic cultural identity. In J. Lindsay \& M. H. T. Liem (Eds.), Hiers to world culture, being Indonesian 1950-1965 (pp. 283-314). Leiden: KITLV Press.

Christantiowati. (1996). Bacaan anak Indonesia tempo doeloe: Kajian pendahuluan periode 19081945. Jakarta, Indonesia: Balai Pustaka.

Faruk. (2012). Metode Penelitian Sastra. Yogyakarta, Indonesia: Pustaka Pelajar.

Foucault, M. (2008). Ingin Tahu Sejarah Seksualitas. Jakarta: Yayasan Obor Indonesia, FIB Universitas Indonesia, Forum Jakarta-Paris.

Foucault, M. (2012). Arkeologi Pengetahuan. Yogyakarta, Indonesia: IRCisoD.

Foulcher, K. (1987). Sastra kontekstual: Recent developments in Indonesian literary politicis. RIMA, 21, 6-28.

Hill, D. T. (1993). The two leading institutions; Taman Ismail Marzuki and Horison. In V. M. Hooker (Ed.). Culture and society in New Order Indonesia (pp. 245-262). Kuala Lumpur: Oxford University, South-East Asian Social Science Monographs.

Ismail, T., \& Moeljanto. D. S. (1995). Prahara Budaya Kilas Balik Offensif Lekra/PKI DKK. Bandung, Indonesia: Mizan.

Isnaniah, S. (2014). Representasi ajaran Islam dalam novel-novel karya Habiburrahman El 
Shirazy, Kajian Sosiologi Sastra dan Nilai-Nilai Pendidikan. Universitas Sebelas Maret, Kota Surakarta, Indonesia.

Jedamski, D. (1992). Balai Pustaka: A colonial wolf in sheep's clothing. Archipel, 44(23-46).

Jones, T. (2015). Kebudayaan dan kekuasaan di Indonesia, kebijakan budaya selama abad ke20 hingga Era Reformasi (translatio; R. E. Terre, Ed.). Jakarta, Indonesia: Yayasan Obor Indonesia.

Kholil, M. I. (2011). Persoalan limitasi budaya dan sastra Islam. Lingua, Jurnal Ilmu Bahasa dan Sastra, 1(2), 71-85.

Partiningsih. (2015). Sastra Anak Balai Pustaka tahun 80-an sebagai propaganda pembangunan orde baru: Kajian wacana Foucault. Jakarta, Indonesia: Universitas Gadjah Mada.

Salam, A. (2004). Oposisi sastra sufi. Yogyakarta, Indonesia: LKIS.

Simuh. (1995). Sufisme Jawa transformasi tasawuf Islam ke mistik Jawa. Yogyakarta, Indonesia: Bentang.

Supangkat, J. (1990). The two forms of Indonesian art. In J. Fischer (Ed.), Modern Indonesian art: Three generations of traditional and change, 1945-1980. Jakarta \& New York: Festival of Indonesia, Panitia Pameran KIAS.

Susanto, D. (2015). Kamus istilah sastra. Yogyakarta, Indonesia: Pustaka Pelajar.

Susanto, D. (2018). Lekra, Lesbumi, Manifes Kebudayaan, Sejarah Sastra Indonesia Periode 1950-1965. Yogyakarta, Indonesia: CAPS (Center for Academic Publishing Service).

Susanto, D., \& Wati, R. (2019). Wacana romantisme dalam sejarah sastra Indonesia periode kolonial Belanda (1900-1942). KEMBARA: Jurnal Keilmuan Bahasa, Sastra, dan Pengajarannya, 5(1), 40-52.Vol.5. No. 1, 40-52.

Syaifudin, H. (2002). Sastra dan Islam, catatan seputar dialektika sistem nilai. El Harakah, Jurnal Budaya Islam, 4(2), 43-52.

Toer, P. A. (1981). Manuscripts banned and destroyed. Sage Journal, 10(6), 35-37.

Wahyuningsih, S. (2015). Representasi pesan-pesan dakwah dalam filem Ayat-ayat Cinta. Karsa: Journal of Social and Islamic Culture, 21(3), 315-339. 